\title{
Role of nucleus accumbens glutamatergic plasticity in drug addiction
}

This article was published in the following Dove Press journal:

Neuropsychiatric Disease and Treatment

27 September 2013

Number of times this article has been viewed

\section{Gabriel C Quinterol-3}

'Florida State University - Panama, Clayton, Panama; ${ }^{2}$ Medical University of South Carolina, Charleston, South Carolina, USA; ${ }^{3}$ Smithsonian Tropical Research Institute, Ancon, Republic of Panama
Correspondence: Gabriel Quintero Florida State University - Panama, Building 227, Clayton, Ciudad del Saber, Republic of Panama Email gquintero@fsu.edu
Abstract: Substance dependence is characterized by a group of symptoms, according to the Diagnostic and Statistical Manual of Mental Disorders, 4th Edition, Text Revision (DSM-IV-TR). These symptoms include tolerance, withdrawal, drug consumption for alleviating withdrawal, exaggerated consumption beyond original intention, failure to reduce drug consumption, expending a considerable amount of time obtaining or recovering from the substance's effects, disregard of basic aspects of life (for example, family), and maintenance of drug consumption, despite facing adverse consequences. The nucleus accumbens (NAc) is a brain structure located in the basal forebrain of vertebrates, and it has been the target of addictive drugs. Different neurotransmitter systems at the level of the NAc circuitry have been linked to the different problems of drug addiction, like compulsive use and relapse. The glutamate system has been linked mainly to relapse after drug-seeking extinction. The dopamine system has been linked mainly to compulsive drug use. The glutamate homeostasis hypothesis centers around the dynamics of synaptic and extrasynaptic levels of glutamate, and their impact on circuitry from the prefrontal cortex (PFC) to the NAc. After repetitive drug use, deregulation of this homeostasis increases the release of glutamate from the PFC to the NAc during drug relapse. Glial cells also play a fundamental role in this hypothesis; glial cells shape the interactions between the PFC and the NAc by means of altering glutamate levels in synaptic and extrasynaptic spaces. On the other hand, cocaine self-administration and withdrawal increases the surface expression of subunit glutamate receptor 1 (GluA1) of alpha-amino-3-hydroxy-5-methyl-4-isoxazolepropionic acid (AMPA) receptors at the level of the NAc. Also, cocaine self-administration and withdrawal induce the formation of subunit glutamate receptor 2 (GluA2), lacking the $\mathrm{Ca}^{2+}$-permeable AMPA receptors (CP-AMPARs) at the level of the NAc. Antagonism of the CP-AMPARs reduces cravings. It is necessary to pursue further exploration of the AMPA receptor subunit composition and variations at the level of the NAc for a better understanding of glutamatergic plastic changes. It is known that cocaine and morphine are able to induce changes in dendritic spine morphology by modifying actin cycling. These changes include an initial increase in spine head diameter and increases in AMPA receptor expression, followed by a second stage of spine head diameter retraction and reduction of the AMPA receptors' expression in spines. Besides glutamate and dopamine, other factors, like brain-derived neurotrophic factor (BDNF), can influence NAc activity and induce changes in dendritic spine density. BDNF also induces drug-related behaviors like self-administration and relapse. Neither apoptosis nor neurogenesis plays a relevant role in the neurobiological processes subjacent to cocaine addiction in adults (rodent or human). Different therapeutic drugs like $\mathrm{N}$-acetylcysteine (NAC), modafinil, acamprosate, and topiramate have been tested in preclinical and/or clinical models for alleviating drug relapse. Moreover, these therapeutic drugs target the glutamatergic circuitry between the PFC and the NAc. NAC and acamprosate have shown inconsistent results in clinical trials. Modafinil and topiramate have shown some success, but more clinical trials are necessary. Based on the current review 
findings, it could be recommendable to explore therapeutic approaches that include synergism between different drugs and neurotransmitter systems. The discrepancy in the results of some therapeutic drugs between preclinical versus clinical trials for alleviating relapse or drug dependence could be linked to the scarce exploration of preclinical models that mimic polydrug abuse patterns, for example, cocaine plus alcohol. At the clinical level, the pattern of polydrug consumption is a phenomenon of considerable frequency. Finally, as a complement at the end, an updated summary is included about the role of glutamate in other neuropsychiatric disorders (for example, mood disorders, schizophrenia, and others).

Keywords: glutamate, drug addiction, nucleus accumbens

\section{Glutamate and drug addiction}

An understanding of glutamate's role in the drug reinstatement process is useful for understanding why drugs targeted toward the glutamatergic system are being used. It is accepted that the dopaminergic system's activity at the level of the nucleus accumbens (NAc) mediates compulsive use of a drug; whereas, the glutamatergic system's activity at the level of the NAc mainly controls relapse after drug extinction. ${ }^{1,2}$ It is already known that glutamate-related plastic changes in the circuitry from the prefrontal cortex (PFC) to the NAc are essential for drug relapse; ${ }^{2}$ the glial cells modulate these circuitry-shaping glutamatergic plastic changes. ${ }^{2}$ Also, the astrocytes are the glial cells that mainly influence glutamate dynamics in addiction by means of activities of the catalytic subunit of the cysteine-glutamate exchanger (xCT) and glutamate transporter 1 (GLT-1). ${ }^{3-5}$ However, further exploration of the role of other glial cells, like the microglia and the oligodendrocytes, in the drug addiction's processes are still necessary.

On the other hand, it is also recognized that cocaine self-administration and withdrawal increases the surface expression of glutamate receptor subunit 1 (GluA1) of the alpha-amino-3-hydroxy-5-methyl-4-isoxazolepropionic acid (AMPA) receptors and fosters the formation of subunit GluA2 lacking $\mathrm{Ca}^{2+}$-permeable AMPA receptors (CP-AMPARs) in the NAc; blocking CP-AMPARs decreases the expression of craving. ${ }^{6-8}$ However, it is useful to further explore AMPA receptors' subunit composition and modifications across different stages (drug-naïve, drug intake, drug withdrawal, and relapse) for obtaining a better understanding of the glutamatergic plastic changes in the NAc.

Moreover, it is proven that cocaine self-administration increases brain-derived neurotrophic factor (BDNF) levels in the NAc, and this rise in BDNF leads to the temporary increase of GluA1 surface expression in the NAc. ${ }^{9}$ Moreover, BDNF can alter dendritic and spine morphology, based on culture studies on the hippocampus. ${ }^{10,11}$ However, whether the mediation of BDNF in morphological changes occurs at the level of the NAc has not yet been explored.
Recent work has contrasted the distribution of AMPA receptor subunits in synaptic versus extrasynaptic membranes of the NAc. ${ }^{12}$ It is known that prolonged cocaine withdrawal increases levels of phosphorylated S845 GluA1 in the NAc extrasynapses. ${ }^{13}$ It is also accepted that extrasynaptic metabotropic glutamate receptor 2 (GRM2) and metabotropic glutamate receptor 3 (GRM3) in the NAc can influence drug relapse. ${ }^{14}$ However, further research is still necessary to determine the interaction between extrasynaptic AMPA receptors (phosphorylated S845 GluA1), GRM2 and GRM3 in the NAc during cocaine withdrawal and relapse.

It is accepted that dopamine agonism in the NAc induces reinstatement, independently of glutamate. ${ }^{15} \mathrm{~A}$ point of interaction between glutamatergic and dopaminergic systems in the NAc is $\mathrm{Ca}^{2+}$ /calmodulin-dependent protein kinase 2 (CaMKII). ${ }^{15}$ Future research could explore combined treatments for drug relapse that target glutamate and dopamine dynamics in the NAc. CaMKII could be a potential target for the focus of further research.

The NAc is a vertebrate's brain region located in the basal forebrain, rostral to the preoptic area. The NAc is also found in other vertebrates like rodents. ${ }^{16}$ The NAc is the main target for addictive drugs (for example, nicotine, cocaine, and amphetamines). It is divided in two main functional areas: the NAc shell (NAcs) and the NAc core (NAcc). ${ }^{16}$ The NAcs contains broad connections to the limbic system and the hypothalamus. ${ }^{16}$ Besides addiction, the NAc plays a relevant role in reward, fear, placebo effect, impulsivity, learning, and aggression. ${ }^{17,18}$

Rodent research by means of microdialysis suggests that after injection of addictive drugs like heroin, cocaine, nicotine, or alcohol in rats, there is an increase in the levels of dopamine in the extracellular area of the NAc. ${ }^{1}$ This increase in dopamine has been linked to the reinforcing effects that subsequently foster drug-taking behavior. ${ }^{1}$ On the other hand, functional imaging studies in humans have shown that environmental cues that are associated with addictive drugs release dopamine in the NAc. ${ }^{1}$ The current review centers around the relationship between the glutamatergic system at the level of the NAc and drug relapse; however, it is impor- 
tant to distinguish that the dopamine dynamics in the NAc predominately mediates changes in the brain associated with the compulsive use of a drug. Alternatively, the glutamate dynamics in the NAc mediates mainly drug-seeking behavior after extinction.

According to the Diagnostic and Statistical Manual of Mental Disorders, 4th Edition, Text Revision (DSM-IV-TR), some of the symptoms linked to the consumption of drugs are impairment in cognition or mood, anxiety, hallucinations, delusions, and seizures. ${ }^{19}$ On the other hand, the essential characteristic of substance dependence is a group of physiological, conductive, and cognitive symptoms, indicating that the individual continues the use of the substance, despite facing substance-related problems. Moreover, substance dependence is characterized by a pattern of repeated selfadministration. This can induce tolerance, withdrawal, and compulsive drug-taking behavior. ${ }^{19}$ According to the DSMIV-TR, substance dependence is characterized by seven main criteria. ${ }^{19}$ Criterion 1 is tolerance; it is defined as the necessity for augmenting the quantity of substance for obtaining the desired effects of the substance. ${ }^{19}$ Tolerance varies across substances.

Criterion 2a is withdrawal. It consists of a dysfunctional behavioral change with cognitive or physiological concomitants, which are triggered after the decline of body levels of a substance that has been consumed constantly by the subject. ${ }^{19}$ Because of the aversive withdrawal symptoms, the subject is likely to consume the substance for alleviating or decreasing the symptoms (criterion 2b). ${ }^{19}$ The withdrawal symptoms vary across substances.

Criterion 3 is a pattern of compulsive substance use. The subject may take the substance in larger quantities or over a longer period of time than originally planned. ${ }^{19}$ Criterion 4 is related to subject failure in decreasing or discontinuing drug use. ${ }^{19}$ Moreover, the subject can spend a considerable amount of time obtaining the substance, consuming it, or alleviating from the effects of the substance (criterion 5). ${ }^{19}$ Criterion 6 can be explained as a subject's disregard for social, familiar, and work-related activities, because the substance has become the center of the subject's life. ${ }^{19}$ Finally, criterion 7 is that the person continues the use of the substance, despite facing adverse consequences (psychological or physical). ${ }^{19}$

According to Kalivas and O'Brien, ${ }^{20}$ drug addiction can be defined as an alteration in the control over the pattern of responses to drug reinforcement. ${ }^{20}$ The brain circuitry most relevant to sustained drug seeking is mainly composed of projections from the PFC to the NAc, but also of complementary projections from the amygdala and the hippocampus to the
NAc. ${ }^{20}$ Specifically, studies have shown that the amygdala is related to the cue-induced relapse of cocaine seeking. The authors also have shown that electrical stimulation of the hippocampus reinstates cocaine-seeking behaviors..$^{21,22}$

Glutamate is the main and most abundant excitatory neurotransmitter in the brain. It is fundamental for the execution of the synaptic plasticity processes that allow the organism to respond and to survive in the environment. ${ }^{23,24}$ These synaptic plasticity processes have been extensively reviewed by Kalivas et al. ${ }^{24}$ The synaptic plasticity mediated by glutamatergic receptors plays a role in drug addiction and other disorders like levodopa-induced dyskinesia, neuropathic pain, schizophrenia, and dementia. ${ }^{23}$ Glutamate homeostasis in the brain and its deregulation are, respectively, related to normal and abnormal behavioral adaptations to the environment. ${ }^{24}$ Besides glutamate and dopamine, other neurotransmitters - like norepinephrine and serotonin - can modulate the reinstatement of cocaine-seeking behavior. ${ }^{25,26}$

At a more cellular level, the glutamate effects of addiction are the results of neuronal and glial interactions, mainly at the level of the NAc. ${ }^{5}$ Chronic drug intake patterns lead to the disruption in the release of glutamate from the PFC to the NAc, which subsequently affects glutamate homeostasis in the NAc, leading to an increase in addictive behavior, mainly relapse. ${ }^{5,27}$ Specifically, this disruption in glutamate homeostasis consists of a decrease in extrasynaptic glutamate concentrations that subsequently lead to decreased tone on presynaptic tone on presynaptic GRM2 and GRM3.28 Because presynaptic GRM2 and GRM3 have inhibitory effects on glutamate presynaptic release, the decrease in tone over GRM2 and GRM3 due to low glutamate perisynaptic levels releases the inhibitory effect of GRM2 and GRM3. As a consequence, it allows for an increase in glutamate release when PFC-NAc projections are activated during the drug-seeking behavior. ${ }^{14}$

As a result of the repetitive use of drugs, alterations in the glutamate levels in the presynaptic terminal increase the activation of the postsynaptic terminal AMPA receptors; specifically, it has been shown to increase in surface expression of GluA1 of the AMPA receptor after cocaine self-administration and withdrawal and, consequently, postsynaptic terminal potentiation in the NAc. ${ }^{6,7}$ In addition, another related study ${ }^{15}$ found that cocaine reinstatement was decreased when the GluA1-containing AMPA receptors' transport was impaired by the infusion of the adenoassociated virus 10-GluA1-C99 vector. Because cocaine reinstatement is linked to an increase in the cell-surface expression of the GluA1-containing AMPA receptors in the 
NAcs, then the antagonizing effect of the adeno-associated virus 10-GluA1-C99 vector on cocaine reinstatement could be explained by the impairment in the transport of AMPA receptors containing GluA1. ${ }^{15}$

Cocaine reinstatement is associated with dopamine type 1 receptor $\left(\mathrm{D}_{1}\right)$-dependent increases in the NAcs, CaMKII phosphorylated on Thr286, and increases in GluA1 phosphorylated on Ser831 (a known CaMKII phosphorylation site), in addition to increases in the cell-surface expression of GluA1-containing AMPA receptors in the shell.

Another similar study found that the infusion of glutamate receptor agonist, AMPA, in the NAc induced cocaine reinstatement; reciprocally, injection of the AMPA receptor antagonist 6-cyano-7-nitroquinoxaline-2,3-dione blocked reinstatement. ${ }^{29}$

Drug-induced AMPA receptor plasticity has been studied extensively in the NAc. ${ }^{30,31}$ The major functional AMPA receptor population in the NAc consists of subunits glutamate receptors 1 and 2 (GluA1A2); the population of subunit glutamate receptors 2 and 3 (GluA2A3) is also present. ${ }^{32}$ On the other hand, the population of of subunits glutamate receptors 4 (GluA4) is very scarce. ${ }^{32}$ It is thought that most of the AMPA receptors' transmissions in the NAc are mediated by the populations of GluA1A2, but GluA2A3 and GluA1A3 also play a significant role in receptor transmission, and even cocaine self-administration is able to alter GluA3 surface expression. ${ }^{6,33}$ Some authors have pointed out the necessity of elucidating AMPA receptor subunit composition in the NAc and in other brain areas related to addiction in the normal brain to be able to understand subsequent abnormal functionality in these regions. ${ }^{32}$

In adult rats, it has been demonstrated that after withdrawal from prolonged cocaine self-administration, there is the formation of subunit GluA2-lacking CP-AMPARs in the NAc; the blocking of these CP-AMPARs reduces the expression of incubating cue-induced craving in rats. ${ }^{6,8}$ This increase in CP-AMPARs observed in both the NAcc and in the NAcs depends on the pattern of contingency of cocaine administration; if cocaine is administered to the rat in a noncontingent treatment, there is no increase in CPAMPARs. ${ }^{8}$ It seems that the CP-AMPA receptor formation can be modulated by both patterns of drug exposure and withdrawal from the drug.

Another line of studies has shown increases in NAc AMPA receptors induced by BDNF. ${ }^{9}$ Specifically, BDNF infusion in the NAcc - but not in the NAcs of the rats rapidly increases (30 minutes) GluA1 surface expression by means of protein synthesis and extracellular receptor kinase-dependent mechanisms. ${ }^{9}$ However, this effect is transient, and no further changes are observed afterward. ${ }^{9}$ This suggests a potential link between cocaine intake, elevation in endogenous BDNF, enhanced AMPA receptor transmission in the NAc, and a possible mechanism through which BDNF could modulate cocaine intake in rats.

Furthermore, chronic stimulant consumption leads to changes in dendritic branching and spine density, and it also augments the level of BDNF in the brain areas related to reward. ${ }^{34,35} \mathrm{~A}$ review of different studies using conditional deletion models of BDNF and its receptor, tyrosine kinase B (TrkB), has supported their relevance in changes of spine density and spine maintenance during development and adulthood stages. ${ }^{10}$ Moreover, hippocampal culture studies support the role of BDNF in protein synthesis-dependent enlargement of individual dendritic spines. ${ }^{11}$ This suggests that the BDNF pathway could contribute to alterations in spine density and dendritic branching associated with consumption of the stimulant. However, further research exploring the direct mediation of the BDNF pathway on the morphological changes in the NAc after drug intake should be pursued. BDNF administration in the brain areas related to addiction (the ventral tegmental area or the NAc) increases the frequency of behaviors related to addiction like locomotion, cocaine-seeking, cocaine self-administration, and relapse; reciprocally, a decrease in BDNF is linked to opposite behaviors. ${ }^{36-39}$

Another interesting study ${ }^{12}$ has elucidated the distribution of AMPA receptor subunits in synaptic versus extrasynaptic membranes at the level of the NAc. Specifically, GluA1 phosphorylated at the protein kinase A (PKA) site (S) 845 is highly expressed in extrasynaptic membranes. Moreover, according to in vitro studies, the dynamic incorporation of the GluA1-containing AMPA receptors into the synapses follows a two-phase process. The first phase consists of the insertion of GluA1-containing AMPA receptors onto the extrasynaptic surface, fostered mainly by phosphorylation of GluA1 at Serine 845 by PKA. The second phase lies in the subsequent relocation of GluA1-containing AMPA receptors to synaptic membrane surface, and it is mediated by N-methyl-D-aspartate (NMDA) receptors. ${ }^{31,40}$ This mechanism of insertion from the extrasynapses to the synapses is mediated by PKA and NMDA, and it is also well-observed in other brain regions, as some authors have pointed out. ${ }^{31,41-44}$ For instance, it has been found in the hippocampus that stabilization of CP-AMPARs in extrasynapses is mediated by PKA phosphorylation on Ser845 GluA1; then, there is the possibility that an increase in CP-AMPARs in the NAc after prolonged withdrawal from 
extended cocaine self-administration is mediated by the same mechanism of PKA phosphorylation. ${ }^{6,45-47}$ In effect, a study reported an increase in phosphorylated S845 GluA1 levels in the NAc extrasynapses after prolonged withdrawal of cocaine, supporting this idea. ${ }^{13}$

Transmembrane AMPA receptor regulatory proteins (TARPs) are another group of proteins that regulate glutamate affinity, channel properties, and AMPA-receptor trafficking. ${ }^{48}$ At the level of the NAc, the role of TARPs has been elucidated by the work of Ferrario et al; ${ }^{12}$ specifically, this work showed that TARPs $\gamma-2$ were enriched in the synaptic membranes, whereas TARPs $\gamma$-4 were mainly located in the extrasynaptic membranes. ${ }^{12}$ This suggests comparatively larger ion flow through the extrasynaptic AMPA receptors. ${ }^{12}$ The larger ion flow through the extrasynaptic AMPA receptors (TARPs $\gamma$-4) compared to synaptic AMPA receptors (TARPs $\gamma$-2) is explained because the TARPs $\gamma-4$ have a more robust enhancement of AMPA receptor transmission when compared to TARPs $\gamma-2$. $^{48}$

Another study found differences in the surface expression of AMPA receptors between single and multiple cocaine injections in rats. A single injection of cocaine increases AMPA receptor surface expression at 24 hours, but not at 2 hours. $^{49}$ On the other hand, surface AMPA receptors increased after withdrawal from cocaine sensitization, but later decreased in sensitized rats 24 hours after the challenge. ${ }^{49}$ In addition, that study found that D2 receptors selective agonism by means of quinpirole intraperitoneal (ip) reduced surface expression of AMPA receptors in the NAc; however, the $D_{1}$ receptors' selective agonism by means of subcutaneous SKF-81297 and mixed $\mathrm{D}_{1}+\mathrm{D}_{2}$ agonism by means of subcutaneous apomorphine did not induce the mobilization of GluA1 and GluA2 from the surface to the intracellular pools of the NAc. ${ }^{49}$

A major review on AMPA receptors and the NAc has pointed out that alterations in the AMPA receptors' transmission in the NAc after cocaine administration depend upon different factors, like contingency of the exposure, withdrawal duration, existence of extinction training, or even the existence of cues paired with cocaine. ${ }^{31}$ It is evident that alterations in the AMPA receptors' transmission in the NAc depend on the contingency of both previous cocaine exposure and withdrawal exposure. Moreover, this review concluded the necessity of not assuming that cocaine and methamphetamines have the same effects on AMPA receptor plasticity at the level of the NAc. ${ }^{31}$

The GluA2 AMPA receptors in the core or shell of the NAc also mediate a cocaine-primed reinstatement of cocaine- seeking behaviors. ${ }^{50}$ Specifically, a study by Famous et $\mathrm{al}^{50}$ reported that antagonism of the AMPA/kainate receptor by 6-cyano-7-nitroquinoxaline-2,3-dione in the NAcc or the NAcs dose dependently reduced cocaine-primed reinstatement in rats. Also, the same study found that the disruption of GluA2 trafficking by the peptide Pep2-EVKI into the NAcc or the NAcs attenuated cocaine-induced the reinstatement of drug-seeking behaviors. ${ }^{50}$

Furthermore, a study ${ }^{51}$ reported that metabotropic glutamate receptor 5 (GRM5) at the level of the postsynaptic terminal participates in cocaine reinforcement and reinstatement. ${ }^{51}$ Specifically, infusion of GRM5 antagonist, 2-methyl6-(phenylethynyl)pyridine (MPEP) $(1 \mu \mathrm{g} / 0.5 \mu \mathrm{L})$, into the NAcs diminishes cocaine priming-induced reinstatement of drug seeking. ${ }^{51}$ This study also reported that MPEP and 3-((2-methyl-1,3-thiazol-4-yl)ethynyl) pyridine (MTEP) administered intraperitoneally, dose-dependently attenuated reinstatement of cocaine seeking, induced by cocaine priming injection. ${ }^{51}$

It is recognized that besides glutamate, the increase of dopamine levels in the NAc is also related to cocaine seeking, based on animal model of relapse. Both neurotransmitters - glutamate and dopamine - can induce relapse independently. ${ }^{15}$ Moreover, an elegant study by Anderson et $\mathrm{al}^{15}$ elucidated that the interaction between both neurotransmitters in the NAc were mediated by CaMKII. Specifically, that study showed that cocaine reinstatement was associated with an increase in $\mathrm{D}_{1}$-like dopamine receptor stimulation in the NAc, and subsequently, the NAcs's increase in CaMKII phosphorylated on Thr286, and L type $\mathrm{Ca}^{2+}$ channel activation; successively, CaMKII and the L-type $\mathrm{Ca}^{2+}$ channel increased cell-surface expression of GluA1 AMPA receptors in the shell by GluA1 phosphorylation on Ser831 (a CaMKII phosphorylation target site). ${ }^{15}$

Other studies have shown that the antagonism of NMDA by the infusion of the competitive antagonist, AP5, either into the NAcc or the NAcs was able to induce reinstatement of cocaineseeking behavior; however, the AP5 antagonism has stronger effects in the shell compared to the core. ${ }^{52}$ An additional study ${ }^{29}$ found similar results - that the antagonism of the NMDA receptor in the NAc dose dependently reinstated cocaine seeking; however, another study ${ }^{53}$ reported that a microinfusion of the NMDA receptor antagonist, CPP, into the NAc did not affect cocaine-induced drug-seeking behavior. ${ }^{29,53}$

As can be perceived, the role of AMPA, GRM, and NMDA receptors of the NAc in cocaine reinstatement is complex. Some authors have even reported opposing effects of AMPA and NMDA receptors in cocaine reinstatement. ${ }^{53}$ 
In synthesis, as a consequence of repetitive cocaineseeking behaviors and self-administration, there are subsequent alterations in the homeostasis of glutamate's levels on the extrasynapses of the NAc, and as a consequence there is excessive release and synaptic overflow of glutamate during reinstatement. ${ }^{5}$ Glial cells also play a relevant role in the reinstatement phenomenon described, and their role in glutamate plasticity will be discussed further in the next section.

\section{Glial role in glutamatergic plasticity}

The role of glial cells in addiction has been recognized by different authors. ${ }^{14,54,55}$ Astrocytes are the glial cells that mainly control the cellular uptake and release of glutamate, influencing the behaviors of addiction. However, less is known about the role of microglia and oligodendrocytes in drug abuse. Astrocytes are significantly affected by exposure to ethanol and other drugs of abuse.

Studies have shown that XCT and the high-affinity GLT-1 play a fundamental role in the maintenance of glutamate levels in the NAc. ${ }^{28,56,57}$ The $\mathrm{xCT}$ is mainly expressed in glial cells. ${ }^{4,5}$ GLT-1 responsible for the majority of glutamate uptake in the brain, is mostly expressed in glial cells. ${ }^{3}$

At the NAc level, the glutamate level alterations observed after drug self-administration and extinction are explained by dysfunction or impaired expression of the glial xCT. ${ }^{24,28,56}$ The xCT catalyzes a 1:1 stoichiometric release of glutamate in exchange for cysteine uptake. ${ }^{58}$ Research suggests that protein levels of $\mathrm{xCT}$ decrease after 2 to 3 weeks of cocaine or nicotine self-administration. ${ }^{56}$ In normal conditions, $\mathrm{xCT}$ supports steady perisynaptic levels of glutamate; glutamate is detected by GRM2 and GRM3, which have an inhibitory effect on glutamate presynaptic release. ${ }^{14}$ However, during drug relapse, $\mathrm{xCT}$ levels are low, and glutamate perisynaptic levels decrease. ${ }^{14}$ This decrease in glutamate levels induces reduction of glutamatergic tone over GRM2 and GRM3, and it subsequently releases the inhibitory effect of GRM2 and GRM3; as a consequence, it allows an increase in glutamate presynaptic release during drug-seeking behavior. ${ }^{14}$

NAC is an amino acid cysteine prodrug that fosters the synthesis of glutathione. In rodents, systemic administration of NAC has prevented cocaine- and heroinprimed reinstatement by restoring glutamate levels. ${ }^{59,60}$ (S)-4-carboxyphenylglycine, an xCT inhibitor, blocks the effects of the NAC in drug reinstatement after being microinjected into the NAc, proving that the effects of NAC in drug reinstatement are mediated by $\mathrm{xCT} .{ }^{61}$ The effects of NAC on glutamatergic synaptic transmission might also be indirect, by means of releasing glutamate through systemic
$\mathrm{xCT}$ to stimulate extrasynaptic GRMs. ${ }^{5}$ Inhibitors of GRM2 and GRM3 block the capacity of NAC to inhibit cocaineprimed reinstatement, suggesting that the effects of NAC on reinstatement are due to effects on presynaptic group II receptors. ${ }^{62}$ The effects of NAC on reinstatement are on presynaptic GRM2 and GRM3, rather than on postsynaptic terminal receptors or glial receptors. ${ }^{5}$

Glial GLT-1 also helps to maintain control in the levels of glutamate in the extracellular space, limiting neuronal excitotoxicity and the kinetics of receptor activation. ${ }^{5,63}$ GLT-1 influences glutamate levels, and it modulates the glutamatergic extrasynaptic release from xCT. Plus, GLT-1 removes glutamate from the perisynaptic space; in this way, it holds double control over the activation of preextrasynaptic and postextrasynaptic GRMs. Preextrasynaptic GRMs modulate the presynaptic release of glutamate, and postextrasynaptic GRMs modulate synaptic plasticity. ${ }^{5}$ The relevance of GLT-1 in drug addiction has been shown by studies reporting GLT-1 downregulation in the NAcc after nicotine or cocaine self-administration. ${ }^{57,58,64}$ Moreover, ceftriaxone treatment restored the GLT-1 levels in the NAcc of rats that were trained to self-administer cocaine, and it disrupted cue- and cocaineinduced reinstatement of cocaine seeking. ${ }^{58}$

It can be seen that the glia plays a key role in the elevated levels of synaptic glutamate in the NAc during drug reinstatement. Glial influences in reinstatement consist of facilitating the massive release of glutamate from the presynaptic terminal, because there is a decrease of $\mathrm{xCT}$ and GLT-1 levels in the glia. Another impact of glia in reinstatement stems from a decrease in the glutamate's clearance in the postsynaptic extracellular space because of the decrease of GLT-1 levels in glia.

\section{Contributions of changes related to apoptosis and neurogenesis in drug addiction processes}

Human and animal studies suggest that cocaine abuse induces changes in the processes and gene expression related to apoptosis, cell death, and mitochondrial function. ${ }^{65,66}$ Cocaine also induces apoptosis in the brain, based on culture cells and developing brain studies; however, no evidence has been found that cocaine induces marked changes related to apoptosis in the adult brain. ${ }^{67}$ Specifically, a recent study ${ }^{67}$ showed a lack of activation of extrinsic and intrinsic apoptotic pathways in the cerebral cortex of human and rat cocaine addicts. In the brain of cocaine abusers, reductions of the FS7-associated cell surface antigen (Fas) receptor, Fas-associated death domain (FADD) adaptor, and mitochondrial cytochrome c 
were found. These changes are signs of nonapoptotic (neuroplastic changes). However, an increase in the degradation of the nuclear poly (ADP-ribose) polymerase 1 - potential evidence of apoptosis-related cell death ${ }^{67}$ - was found. Similar findings were found in the brain cortex of rats that were cocaine addicts; particularly, a lack of changes in the Fas-FADD receptor complex, mitochondrial cytochrome c, caspase-3/fragments, apoptosis-inducing factor, and the poly (ADP-ribose) polymerase 1 cleavage were observed. However, in rats exposed to chronic cocaine and abstinence, increases in the truncated form of dopamine and cyclic adenosine monophosphate (cAMP) regulated phosphoprotein (t-DARPP) were found in the cerebral cortex. ${ }^{67}$.

Another rat study suggests that neurogenesis is not necessary for the expression of cocaine-induced conditioned place preference. ${ }^{68}$ That study showed that after brain X-irradiation, which reduces progenitor cell proliferation in the lateral ventricles and dentate gyrus, the differences in the expression of cocaineinduced conditioned place preference were not found. ${ }^{68}$

\section{Relationship between plastic changes in medium spiny neurons (MSN), spine morphology, and glutamatergic receptors}

The morphology of dendritic spines basically depends on the interactions between factors that promote or halt the cycling of monomeric globular actin. It has been demonstrated that cocaine and morphine are able to induce changes in the morphology of dendritic spines after withdrawal from chronic noncontingent cocaine (or morphine) administration by means of influencing actin cycling. ${ }^{67,69}$ Chronic cocaine exposure, followed by withdrawal and subsequent acute cocaine administration, induces a two-phase modification process, consisting of an initial increase in spine head diameter (45 minutes after injection), followed by a second phase of spine head retraction in size (120 minutes). In the initial phase, there is an increase in F-actin branching and higher levels of AMPA receptors in the spine; on the other hand, in the second phase, there is an augmented disassembly of F-actin filaments and the reduction of AMPA receptor expression in spines..$^{15,33,70}$ Moreover, it is important to add that - after 24 hours of cocaine administration (chronic noncontingent paradigm) - the surface expression of the GluA1 subunit is reduced, which is in contrast to the initial quick increase of surface AMPA receptors. ${ }^{15,33}$

At a more molecular level, actin endures a cyclical process in which filamentous actin is depolymerized to individual globular actin at one end of the filament, and lengthened by inserting actin monomers into the other end of the filament. ${ }^{71}$ Studies have shown the mechanism by which cocaine and morphine withdrawal modulate the actin cycle dynamic. ${ }^{69}$ Specifically, after cocaine withdrawal, there is a reduction in the LIM kinase, a kinase that inactivates cofilin, an actinbinding protein that controls the disassembly of actin filaments. ${ }^{69,72}$ Then, after chronic cocaine administration, cofilin is released from the inhibitory control of LIM kinase, and it is able to foster the disassembly of actin filaments in individual monomers. Now, for actin monomers to aggregate and form actin branches, it is necessary a previous phosphorylation of Ena and vasodilator-stimulated phosphoprotein (VASP) proteins by means of cocaine. ${ }^{73}$ Ena and VASP proteins are a group of actin-regulatory proteins that have been implicated in actin-based processes like fibroblast migration and axon guidance. Specifically, Ena and VASP proteins link with the barbed ends of actin filaments and antagonize filamentcapping processes. ${ }^{73}$ It is necessary to point out that cocaine also has an opposite effect (an inhibition of branching) that is mediated by a reduction in actin-related protein 3 (ARP 3), and by an increase in the phosphorylation of cortical actinbinding protein (cortactin) - both of which hinder the capacity of cofilin to induce branching. ${ }^{74}$ Then, because cocaine has opposing effects in branching, it is assumed that the facilitator effects in branching induced by the phosphorylation of Ena and VASP surpass the inhibitory effects of branching that are induced by the inhibition of ARP 3 and the phosphorylation of cortactin. ${ }^{73}$

\section{Integrating different approaches}

Different authors ${ }^{7,75-77}$ have tried to integrate main theories about glutamatergic neuroadaptations at the level of the NAc induced by cocaine administration. These include changes in synaptic AMPA receptor levels, changes in extracellular nonsynaptic glutamate levels, and changes in MSN intrinsic membrane excitability. ${ }^{7,75-77}$ Moreover, it has been suggested that further studies could explore alterations in presynaptic inputs to the NAc. ${ }^{75}$

An important take-home message is that high cocaine intake may lead to the formation of CP-AMPARs, as well as its insertion in the synapse, and this increase in CP-AMPARs may endure even if glutamate levels are normalized. This condition could enhance the postsynaptic terminal response to subsequent cocaine intake, independent of the presynaptic glutamate release. ${ }^{75}$ Then, the postsynaptic terminal response in the NAc MSNs is an integration of presynaptic release derived from extrasynaptic glutamate levels (Kalivas' 
hypothesis) and an increase in levels in the AMPA receptors (CP-AMPARs; Wolf group findings). ${ }^{6,14}$ Beyond this, a third triggering factor in the MSN response is the decrease in intrinsic membrane excitability as a consequence of cocaine withdrawal; this decrease results from a decrease in $\mathrm{Na}^{+}$ and $\mathrm{Ca}^{2+}$ conductance and from an increase in $\mathrm{K}^{+}$conductance. ${ }^{76,78-80}$ An important factor is that this decrease in intrinsic excitability is secondary to homeostatic synapse-driven membrane plasticity and to alterations in protein kinase and phosphatase cascades. ${ }^{79,81}$ The homeostatic synapsedriven membrane plasticity is a novel form of homeostatic plasticity and consists of compensatory changes in intrinsic excitability, subsequent to enduring changes in the NMDA receptors' transmission; specifically, it involves SK-type $\mathrm{Ca}^{2+}$-activated $\mathrm{K}^{+}$channels. When excitatory inputs to MSN are elevated, the homeostatic synapse-driven membrane plasticity induces augmentation of the SK channel mediated after hyperpolarization potential.

The relationship between the decrease in intrinsic excitability and cocaine behavioral correlates has been supported by a study in rats overexpressing the $\mathrm{K}^{+}$channel subunit Kir2.1, which denoted an increased locomotion response to a cocaine challenge (sensitization). ${ }^{82}$ Kir2.1 is an inwardly rectifying $\mathrm{K}^{+}$channel subunit that reliably depresses the excitability of several different neuronal cell types when it is experimentally overexpressed. ${ }^{82}$ Additionally, another study ${ }^{77}$ comparing rat strains with high versus low levels of MSNintrinsic excitability, showed that rats with the low excitability strain denoted enhanced cocaine self-administration and locomotor response compared to the high-level group. On the other hand, chronic drug exposure is also related to an increase in the cAMP pathway and in PKA signaling in the NAc. ${ }^{83,84}$ These neuroadaptations in the NAc affect the electrophysiological properties of MSN; specifically, all these increase in the cAMP pathway, and the PKA signaling reduces MSN excitability by means of the direct effects of PKA on ion channels. ${ }^{82}$ However, cAMP and PKA also activate cAMP response element-binding protein (CREB) NAc, with a subsequent dampening of the magnitude of this decrease in excitability. ${ }^{82}$

This suggests that the decrease in MSN excitability led to an increase in cocaine seeking and sensitization, which could seem contradictory. A possible integrative explanation to this is that the decrease in MSN intrinsic excitability boosts the signal-to-noise ratio for cocaine-related stimuli. ${ }^{85}$ Then, this decrease in MSN intrinsic excitability generated by cocaine intake could explain the low behavioral response to normal rewarding stimulus, (stimulus that are non related to cocaine) and this stimulus induces a modest excitatory input. ${ }^{85}$ Also, this decrease in MSN intrinsic excitability generated by cocaine intake could also explain the enhanced behavioral response to cocaine and related stimulus (which are related to stronger excitatory inputs). ${ }^{85}$ Another possible explanation by other authors is that the decrease in excitability during cocaine withdrawal induces a counterbalanced enhancement in synaptic AMPA receptor levels, which is responsible for augmenting response to cocaine and cocaine-related stimuli. $^{82}$

\section{Current status of drugs based on glutamate plasticity in human trials}

Some authors have pointed out recently the relevance of glutamate-based therapies, among others, for treating drug addiction. ${ }^{86,87}$ Plasticity of glutamate has been explored in preclinical models of relapse and in pilot clinical trials; Kalivas and Volkow ${ }^{2}$ have proposed approaches to treat cocaine addiction that integrate presynaptic terminal, postsynaptic terminal, and glial mechanisms. For instance, as previously described, $\mathrm{xCT}$ is altered after chronic drug use, and an attempt to explore this protein for drug treatment has obtained successful results initially. NAC is an amino acid cysteine prodrug that increases the levels of XCT and GLT-1 and promotes the synthesis of glutathione. ${ }^{5,61} \mathrm{NAC}$ has been probed for alleviating drug relapse in preclinical and clinical studies. In a rodent self-administration model of relapse, the NAC systemic administration has prevented cocaine- and heroin-primed reinstatement by restoring glutamate levels. 59,60 In addition, chronic NAC administration following heroin self-administration can prevent reinstatement after 6 weeks of treatment cessation. ${ }^{59,60}$

However, clinical trials with NAC have shown opposite results. A US National Institutes of Health-National Institute on Drug Abuse online report (www.drugabuse.gov/newsevents/nida-notes/2013/01/n-acetylcysteine-postsynapticeffect-limits-efficacy) states that NAC has only moderate efficacy in preventing drug relapse. On the other hand, other studies favor the modulating effect of NAC on drug relapse. Specifically, a study reports that NAC decreases drug desire after cocaine injection. ${ }^{88} \mathrm{~A}$ double-blind research study affirms that NAC (1,200 mg or 2,400 mg) surpasses placebo for the reduction of cocaine relapse if subjects were abstinent the week before treatment. ${ }^{89}$ Moreover, human imaging studies confirm that NAC is able to modify glutamate levels in the brains of cocaine addicts. ${ }^{90,91}$ This opens the possibility that NAC could reduce cocaine relapse by modifying glutamate levels. Specifically, a Dutch study ${ }^{90}$ reported that NAC 
normalizes glutamate levels in cocaine-dependent patients. Further research would be useful to strengthen the use of NAC for treating drug relapse..$^{90}$ Another imaging investigation (magnetic resonance spectroscopy) informs that cocaine addicts experience a reduction of glutamate levels in the anterior cingulate cortex after a unique administration of NAC. ${ }^{91}$

Modafinil, an alpha-adrenergic/glutamate agonist, is another promising treatment for cocaine dependence, which is based on glutamate modulation; it has shown some success in clinical trials. ${ }^{92,93}$ Nevertheless, its subjacent mechanism does not totally rely on glutamate and, rather, can be explained by the synergism of different neurotransmitters (dopamine, glutamate, gamma aminobutyric acid [GABA], noradrenalin, and the hypocretin/orexin system); its mechanism of action needs to be elucidated. ${ }^{93}$ Modafinil has a mechanism of action similar to NAC; it raises the extracellular levels of glutamate, inducing an increase in the glutamatergic tone on presynaptic GRM2 and GRM3. ${ }^{94}$ As already described, GRM2 and GRM3 have inhibitory effects on presynaptic glutamate release, allowing a decrease in glutamate release when the $\mathrm{PFC}-\mathrm{NAc}$ projections are activated during drug-seeking behavior. ${ }^{14}$ The effectiveness of modafinil-reducing cocaine reinstatement has been supported by different studies. ${ }^{94-96}$

Topiramate is another excellent drug for relapse prevention, based on its modulating effects on GABA and glutamate neurotransmissions. ${ }^{97}$ Specifically, at the level of the NAc, it has been shown that topiramate blocks AMPA/ kainate receptors and prevents cocaine relapse in rats. ${ }^{29}$ This is explained because the infusion of cocaine or glutamate receptor agonist, AMPA, into the NAc induces reinstatement; then, the antagonism of the AMPA receptor by topiramate in NAc blocks the reinstatement. ${ }^{29}$ Clinical studies have also supported the reduction in cocaine dependence after topiramate treatment. ${ }^{98}$

Acamprosate is a drug approved by the US Food and Drug Administration for treating alcohol dependence. It is speculated that the acamprosate mechanism of action relies on decreasing glutamatergic tone by antagonizing NMDA receptors or GRM5. ${ }^{99}$ Nevertheless, the effect of acamprosate on glutamate receptors may be dependent on resting NMDA receptor activity; therefore, acamprosate may be better considered as an NMDA partial agonist. ${ }^{99}$ The effect of acamprosate on the relapse of the human alcoholic is inconsistent; some authors report decreases, and others report modest effects in preventing alcohol relapse. ${ }^{100-102}$ On the other hand, a study performed in male and female cocaine-dependent patients reported that acamprosate was not better than a placebo in decreasing cocaine craving and decreasing cocaine withdrawal symptoms. ${ }^{99}$ A diagram representing the main targets of the therapeutic drugs at the level of NAc for alleviating drug relapse is described in Figure 1.

The relapse and drug dependence phenomena involve different neurotransmitter systems besides dopamine and glutamate. In the future, it could be useful to explore more strategies based on synergism. Targeting different neurotransmitters systems (for example, glutamate + GABA; hypocretin + GABA) with lower doses could reduce the risks of undesired side effects. At the same time, considering a different neurotransmitter system could allow for the targeting, possibly, of different mechanisms that reduce drug dependence and relapse. NAC has obtained inconsistent results in human clinical trials, despite promising preclinical results (www.drugabuse.gov/news-events/nida-notes/2013/01/nacetylcysteine-postsynaptic-effect-limits-efficacy). ${ }^{59,60,88,89}$

Also, it is important to consider that human addicts can be polydrug users (individuals who use two or more different drugs). A final question could be if the discrepancy between the results of preclinical and human tests exploring therapeutic drugs (targeting glutamatergic or other systems) could be explained, because preclinical models focus on a single drug of abuse, but human drug problems imply polydrug use patterns. It may be suitable to revise different therapeutic drugs while considering preclinical polydrug models.

\section{Role of glutamate in other neuropsychiatric disorders}

Alterations of the glutamatergic system have been linked to subjacent processes of other neuropsychiatric diseases besides drug addiction problems. Some of these diseases include mood disorders, schizophrenia, depression, Alzheimer's disease, autism spectrum disorders, neuropsychiatric components of lupus, neuropsychiatric components of Fragile $\mathrm{X}$ syndrome (FXS), Parkinson's disease, obsessive-compulsive disorder, and epilepsy. ${ }^{103-117}$

Specifically, in schizophrenia, the involvement of the glutamatergic system has been supported by findings that describe the appearance of schizophrenia-like symptoms after the antagonism of NMDA receptors by means of phencyclidine and ketamine drugs; moreover, additional evidence of the link between the glutamatergic system and schizophrenia comes from reports that describe alterations in gene expression and metabolic pathways related to NMDA receptors in schizophrenics. ${ }^{103,118,119}$ 


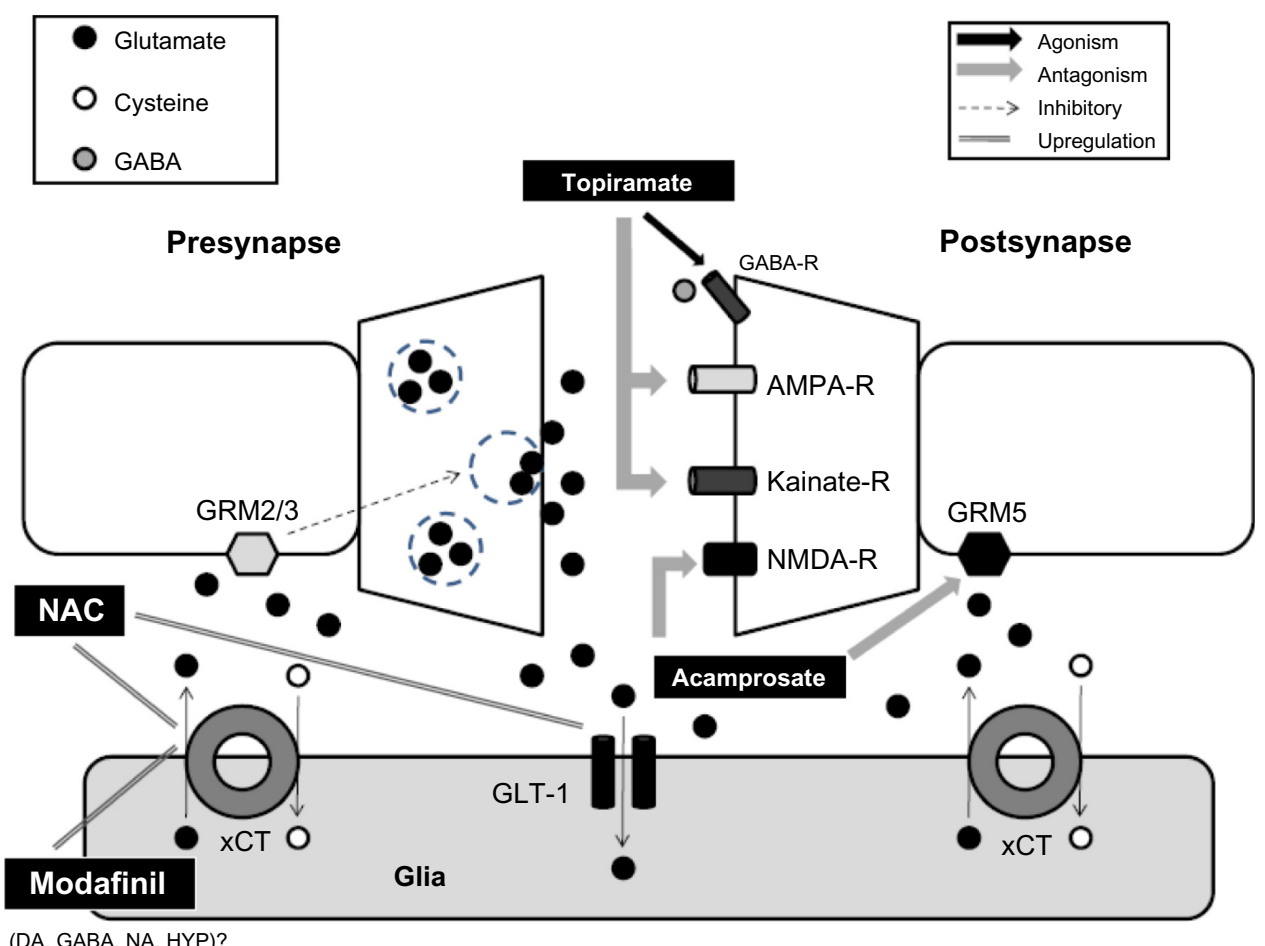

Figure I Main targets of the therapeutic drugs at the level of NAc for alleviating drugs relapse.

Notes: During drug relapse, there is a massive efflux of glutamate from the PFC (presynapse) to the NAc (postsynapse), leading to postsynaptic depolarization. In general, the different therapeutic drugs aim to decrease the postsynaptic depolarization by either reducing the presynaptic release of glutamate or by decreasing postsynaptic depolarization. Agonism of GRM2/3 by extrasynaptic glutamate inhibits glutamate exocytosis. Agonism of GRM5 by extrasynaptic glutamate increases postsynaptic depolarization. GLT-I reduces glutamate levels in the synapse and extrasynapses by transporting it into the glia. The $x C T$ releases glutamate in the extrasynaptic spaces and takes cysteine into the glia. The different therapeutic drugs described in the diagram are topiramate, NAC, modafinil, and acamprosate. Topiramate - by means of agonism on the GABA receptors and by antagonism of the glutamatergic receptors (AMPA and NMDA) - decreases postsynaptic depolarization during relapse. Acamprosate blocks postsynaptic glutamatergic receptors NMDA and GRM5, reducing depolarization in the course of relapse. NAC and modafinil increase levels of $x C T$, and this subsequently raises the extrasynaptic glutamate levels; then, this increase in glutamate strengthens the inhibition of presynaptic GRM2/3 on glutamate exocytosis during relapse. Alternatively, NAC increases GLTI levels; then, the increase in GLT-I reduces the glutamate from the synapse and postsynapse, decreasing depolarization throughout the relapse. On the other hand, modafinil also influences activity of dopamine, GABA, noradrenaline, and hypocretin receptors, but the exact mechanism of action in the NAc is still unknown.

Abbreviations: GABA, gamma aminobutyric acid; GABA-R, gamma aminobutyric acid receptor; GRM, metabotropic glutamate receptors; AMPA-R, alpha-amino-3-hydroxy-5-methyl-4-isoxazolepropionic acid receptor; NMDA-R, N-methyl-D-aspartate receptor; NAC, N-acetylcysteine; $x C T$, glutamate-cysteine exchanger catalytic subunit; GLT-I, glutamate transporter I; DA, dopamine; NA, noradrenaline; HYP, hypocretin; NAc, nucleus accumbens; PFC, prefrontal cortex; AMPA, alpha-amino3-hydroxy-5-methyl-4-isoxazolepropionic acid; NMDA, N-methyl-D-aspartate.

Some mutant mice models have suggested a relationship between the NMDA receptor and schizophrenia. An example would be a mouse mutant with a $90 \%$ reduction of the NMDA receptor, and another mutant mouse with point mutations on the glycine site of the NMDA receptor. ${ }^{120,121}$

Lupus neuropsychiatric symptoms have been linked to alterations in the glutamatergic system. Around one-half of the patients with lupus display neuropsychiatric symptoms; among others alterations, lupus patients show pathogenic autoantibodies that target subunits NR2A and NR2B of the NMDA receptors. In effect, around $50 \%$ of patients with neurolupus have these antibodies in their cerebrospinal fluid. ${ }^{104}$

FXS is a neurodevelopmental disease caused by a disruption in the functioning of the fragile $\mathrm{X}$ mental retardation protein (FMRP). The deficit in FMRP affects metabotropic glutamate receptor (group 1) functioning, which could be the neurobiological substrate of the neuropsychiatric features of FXS. ${ }^{106}$ Moreover, more evidence of the link between glutamate and FXS comes from studies on mutant mice models of FXS, and clinical studies of FXS patients that report improvement of conditions after treatment with allosteric modulators of the metabotropic glutamatergic receptors. ${ }^{106}$

On the other hand, Parkinson's disease alterations are explained not only by alterations of the dopaminergic system, but also by alterations of the glutamatergic system. Positron emission tomography studies in 6-hydroxydopamine (6-OHDA) lesioned rats showed an increase in the uptake of a tracer related to the GRM5 ligand ([11C]-MPEP) in the denervated striatum, hippocampus, and cerebral cortex. ${ }^{122}$ This supports the contribution of a reciprocal relationship between dopamine and glutamate in the basal ganglia and cerebral cortex in the Parkinson's disease pathology ${ }^{123}$ Further evidence is that the antagonism 
of GRM5 (MPEP) decreases the motor deficits of the 6-OHDA lesioned rats. ${ }^{124}$ Moreover, mutant mice lacking GRM5 receptors (knockouts) did not experience the motor dysfunction and neurochemical alterations subsequent to 6-OHDA lesions. ${ }^{125}$

Epilepsy has also been linked to the alterations of the glutamatergic system, specifically kainate receptors. ${ }^{114-116}$ A rodent model of epilepsy that consisted of a decrease in the level of the GluR6 type of receptors has been studied; this rodent model showed reduced susceptibility to kainate-induced seizures. ${ }^{114}$ Moreover, another rodent study reported that the antagonism of GluK1 receptors hinder seizures generated by pilocarpine, supporting a link between the kainate receptors and epilepsy. ${ }^{116}$ Nevertheless, the relevance of kainate receptors in human epilepsy is not so clear. ${ }^{105}$

Obsessive-compulsive disorder has also been linked to alterations in the glutamatergic system, specifically to the kainate type of receptors. ${ }^{11,112}$ In particular, glutamate receptor, ionotropic kainate 2 (GRIK2), has been linked to obsessive-compulsive disorder in studies using single nucleotide polymorphisms. ${ }^{111}$

\section{Acknowledgments}

Thanks to the SENACYT-IFARHU Fellowship (SENACYT

- Secretaria Nacional de Ciencia, Tecnología e Innovación;

IFARHU: Instituto para la Formación y Aprovechamiento de Recursos Humanos), the Programa de Becas de Doctorado y Post-Doctorado, and SNI (Sistema Nacional de Investigación) (SENACYT-Panama) awarded to GCQ. Thanks to Peter W Kalivas (MUSC) for lab facilities and support.

\section{Disclosure}

The author reports no conflicts of interest in this work.

\section{References}

1. Carlson NR. Physiology of Behavior. 11th ed. Boston: Pearson; 2013.

2. Kalivas PW, Volkow ND. New medications for drug addiction hiding in glutamatergic neuroplasticity. Mol Psychiatry. 2011;16(10): 974-986.

3. Haugeto O, Ullensvang K, Levy LM, et al. Brain glutamate transporter proteins form homomultimers. J Biol Chem. 1996;271(44): 27715-27722.

4. Mohan A, Pendyam S, Kalivas PW, Nair SS. Molecular diffusion model of neurotransmitter homeostasis around synapses supporting gradients. Neural Comput. 2011;23(4):984-1014.

5. Reissner KJ, Kalivas PW. Using glutamate homeostasis as a target for treating addictive disorders. Behav Pharmacol. 2010;21(5-6):514-522.

6. Conrad KL, Tseng KY, Uejima JL, et al. Formation of accumbens GluR2lacking AMPA receptors mediates incubation of cocaine craving. Nature. 2008;454(7200):118-121.

7. Moussawi K, Pacchioni A, Moran M, et al. N-Acetylcysteine reverses cocaine-induced metaplasticity. Nat Neurosci. 2009;12(2):182-189.
8. McCutcheon JE, Wang X, Tseng KY, Wolf ME, Marinelli M. Calciumpermeable AMPA receptors are present in nucleus accumbens synapses after prolonged withdrawal from cocaine self-administration but not experimenter-administered cocaine. J Neurosci. 2011;31(15): 5737-5743.

9. Li X, Wolf ME. Brain-derived neurotrophic factor rapidly increases AMPA receptor surface expression in rat nucleus accumbens. Eur $J$ Neurosci. 2011;34(2):190-198.

10. Russo SJ, Mazei-Robison MS, Ables JL, Nestler EJ. Neurotrophic factors and structural plasticity in addiction. Neuropharmacology. 2009;56 Suppl 1:73-82.

11. Tanaka J, Horiike Y, Matsuzaki M, Miyazaki T, Ellis-Davies GC, Kasai H. Protein synthesis and neurotrophin-dependent structural plasticity of single dendritic spines. Science. 2008;319(5870): 1683-1687.

12. Ferrario CR, Loweth JA, Milovanovic M, Wang X, Wolf ME. Distribution of AMPA receptor subunits and TARPs in synaptic and extrasynaptic membranes of the adult rat nucleus accumbens. Neurosci Lett. 2011;490(3):180-184.

13. Ferrario CR, Loweth JA, Milovanovic M, et al. Alterations in AMPA receptor subunits and TARPs in the rat nucleus accumbens related to the formation of $\mathrm{Ca}^{2+}$-permeable AMPA receptors during the incubation of cocaine craving. Neuropharmacology. 2011;61(7):1141-1151.

14. Kalivas PW. The glutamate homeostasis hypothesis of addiction. Nat Rev Neurosci. 2009;10(8):561-572.

15. Anderson SM, Famous KR, Sadri-Vakili G, et al. CaMKII: a biochemical bridge linking accumbens dopamine and glutamate systems in cocaine seeking. Nat Neurosci. 2008;11(3):344-353.

16. Kandel ER, Schwartz JH, Jessell TM. Principles of Neural Science. 4th ed. NY, NY: McGraw Hill; 2000.

17. Schwienbacher I, Fendt M, Richardson R, Schnitzler HU. Temporary inactivation of the nucleus accumbens disrupts acquisition and expression of fear-potentiated startle in rats. Brain Res. 2004;1027(1-2): 87-93.

18. Basar K, Sesia T, Groenewegen H, Steinbusch HW, VisserVandewalle V, Temel Y. Nucleus accumbens and impulsivity. Prog Neurobiol. 2010;92(4):533-557.

19. American Psychiatric Association. Diagnostic and Statistical Manual of Mental Disorders - DSM-IV-TR. 4th ed. Arlington, VA: American Psychiatric Association; 2000.

20. Kalivas PW, O'Brien C. Drug addiction as a pathology of staged neuroplasticity. Neuropsychopharmacology. 2008;33(1):166-180.

21. Grimm JW, See RE. Dissociation of primary and secondary reward-relevant limbic nuclei in an animal model of relapse. Neuropsychopharmacology. 2000;22(5):473-479.

22. Vorel SR, Liu X, Hayes RJ, Spector JA, Gardner EL. Relapse to cocaine-seeking after hippocampal theta burst stimulation. Science. 2001;292(5519):1175-1178.

23. Benarroch EE. NMDA receptors: recent insights and clinical correlations. Neurology. 2011;76(20):1750-1757.

24. Kalivas PW, Lalumiere RT, Knackstedt L, Shen H. Glutamate transmission in addiction. Neuropharmacology. 2009;56 Suppl 1:169-173.

25. Erb S, Hitchcott PK, Rajabi H, Mueller D, Shaham Y, Stewart J. Alpha-2 adrenergic receptor agonists block stress-induced reinstatement of cocaine seeking. Neuropsychopharmacology. 2000;23(2):138-150.

26. Tran-Nguyen LT, Baker DA, Grote KA, Solano J, Neisewander JL. Serotonin depletion attenuates cocaine-seeking behavior in rats. Psychopharmacology (Berl). 1999;146(1):60-66.

27. LaLumiere RT, Kalivas PW. Glutamate release in the nucleus accumbens core is necessary for heroin seeking. $J$ Neurosci. 2008;28(12): 3170-3177.

28. Madayag A, Lobner D, Kau KS, et al. Repeated N-acetylcysteine administration alters plasticity-dependent effects of cocaine. J Neurosci. 2007;27(51):13968-13976.

29. Cornish JL, Kalivas PW. Glutamate transmission in the nucleus accumbens mediates relapse in cocaine addiction. $J$ Neurosci. 2000;20(15):RC89. 
30. Bowers MS, Chen BT, Bonci A. AMPA receptor synaptic plasticity induced by psychostimulants: the past, present, and therapeutic future. Neuron. 2010;67(1):11-24.

31. Wolf ME, Ferrario CR. AMPA receptor plasticity in the nucleus accumbens after repeated exposure to cocaine. Neurosci Biobehav Rev. 2010;35(2):185-211.

32. Reimers JM, Milovanovic M, Wolf ME. Quantitative analysis of AMPA receptor subunit composition in addiction-related brain regions. Brain Res. 2011;1367:223-233.

33. Boudreau AC, Reimers JM, Milovanovic M, Wolf ME. Cell surface AMPA receptors in the rat nucleus accumbens increase during cocaine withdrawal but internalize after cocaine challenge in association with altered activation of mitogen-activated protein kinases. J Neurosci. 2007;27(39):10621-10635.

34. Robinson TE, Kolb B. Structural plasticity associated with exposure to drugs of abuse. Neuropharmacology. 2004;47 Suppl 1:33-46.

35. Thomas MJ, Kalivas PW, Shaham Y. Neuroplasticity in the mesolimbic dopamine system and cocaine addiction. Br J Pharmacol. 2008;154(2): 327-342.

36. Lu L, Dempsey J, Liu SY, Bossert JM, Shaham Y. A single infusion of brain-derived neurotrophic factor into the ventral tegmental area induces long-lasting potentiation of cocaine seeking after withdrawal. J Neurosci. 2004;24(7):1604-1611.

37. Horger BA, Iyasere CA, Berhow MT, Messer CJ, Nestler EJ, Taylor JR. Enhancement of locomotor activity and conditioned reward to cocaine by brain-derived neurotrophic factor. J Neurosci. 1999;19(10): 4110-4122.

38. Hall FS, Drgonova J, Goeb M, Uhl GR. Reduced behavioral effects of cocaine in heterozygous brain-derived neurotrophic factor (BDNF) knockout mice. Neuropsychopharmacology. 2003;28(8): 1485-1490.

39. Graham DL, Edwards S, Bachtell RK, DiLeone RJ, Rios M, Self DW. Dynamic BDNF activity in nucleus accumbens with cocaine use increases self-administration and relapse. Nat Neurosci. 2007;10(8): 1029-1037.

40. Sun X, Milovanovic M, Zhao Y, Wolf ME. Acute and chronic dopamine receptor stimulation modulates AMPA receptor trafficking in nucleus accumbens neurons cocultured with prefrontal cortex neurons. J Neurosci. 2008;28(16):4216-4230.

41. Heine M, Groc L, Frischknecht R, et al. Surface mobility of postsynaptic AMPARs tunes synaptic transmission. Science. 2008;320(5873): 201-205.

42. Makino H, Malinow R. AMPA receptor incorporation into synapses during LTP: the role of lateral movement and exocytosis. Neuron. 2009;64(3):381-390.

43. Yang Y, Wang XB, Frerking M, Zhou Q. Delivery of AMPA receptors to perisynaptic sites precedes the full expression of long-term potentiation. Proc Natl Acad Sci U S A. 2008;105(32):11388-11393.

44. Man HY, Sekine-Aizawa Y, Huganir RL. Regulation of \{alpha $\}$-amino3-hydroxy-5-methyl-4-isoxazolepropionic acid receptor trafficking through PKA phosphorylation of the Glu receptor 1 subunit. Proc Natl Acad Sci U S A. 2007;104(9):3579-3584.

45. Guire ES, Oh MC, Soderling TR, Derkach VA. Recruitment of calciumpermeable AMPA receptors during synaptic potentiation is regulated by CaM-kinase I. J Neurosci. 2008;28(23):6000-6009.

46. Yang Y, Wang XB, Zhou Q. Perisynaptic GluR2-lacking AMPA receptors control the reversibility of synaptic and spines modifications. Proc Natl Acad Sci U S A. 2010;107(26):11999-12004.

47. Mameli M, Halbout B, Creton C, et al. Cocaine-evoked synaptic plasticity: persistence in the VTA triggers adaptations in the NAc. Nat Neurosci. 2009;12(8):1036-1041.

48. Kato AS, Gill MB, Yu H, Nisenbaum ES, Bredt DS. TARPs differentially decorate AMPA receptors to specify neuropharmacology. Trends Neurosci. 2010;33(5):241-248.

49. Ferrario CR, Li X, Wolf ME. Effects of acute cocaine or dopamine receptor agonists on AMPA receptor distribution in the rat nucleus accumbens. Synapse. 2011;65(1):54-63.
50. Famous KR, Kumaresan V, Sadri-Vakili G, et al. Phosphorylationdependent trafficking of GluR2-containing AMPA receptors in the nucleus accumbens plays a critical role in the reinstatement of cocaine seeking. J Neurosci. 2008;28(43):11061-11070.

51. Kumaresan V, Yuan M, Yee J, et al. Metabotropic glutamate receptor 5 (mGluR5) antagonists attenuate cocaine priming- and cue-induced reinstatement of cocaine seeking. Behav Brain Res. 2009;202(2): 238-244.

52. Famous KR, Schmidt HD, Pierce RC. When administered into the nucleus accumbens core or shell, the NMDA receptor antagonist AP-5 reinstates cocaine-seeking behavior in the rat. Neurosci Lett. 2007;420(2):169-173.

53. Park WK, Bari AA, Jey AR, et al. Cocaine administered into the medial prefrontal cortex reinstates cocaine-seeking behavior by increasing AMPA receptor-mediated glutamate transmission in the nucleus accumbens. J Neurosci. 2002;22(7):2916-2925.

54. Vijayaraghavan S. Glial-neuronal interactions - implications for plasticity and drug addiction. AAPS J. 2009;11(1):123-132.

55. Miguel-Hidalgo JJ. The role of glial cells in drug abuse. Curr Drug Abuse Rev. 2009;2(1):72-82.

56. Knackstedt LA, Moussawi K, Lalumiere R, Schwendt M, Klugmann M, Kalivas PW. Extinction training after cocaine self-administration induces glutamatergic plasticity to inhibit cocaine seeking. J Neurosci. 2010;30(23):7984-7992.

57. Knackstedt LA, LaRowe S, Mardikian P, et al. The role of cystineglutamate exchange in nicotine dependence in rats and humans. Biol Psychiatry. 2009;65(10):841-845.

58. Knackstedt LA, Melendez RI, Kalivas PW. Ceftriaxone restores glutamate homeostasis and prevents relapse to cocaine seeking. Biol Psychiatry. 2010;67(1):81-84.

59. Zhou W, Kalivas PW. N-acetylcysteine reduces extinction responding and induces enduring reductions in cue- and heroin-induced drugseeking. Biol Psychiatry. 2008;63(3):338-340.

60. Murray JE, Everitt BJ, Belin D. N-Acetylcysteine reduces early- and late-stage cocaine seeking without affecting cocaine taking in rats. Addict Biol. 2012;17(2):437-440.

61. Kau KS, Madayag A, Mantsch JR, Grier MD, Abdulhameed O, Baker DA. Blunted cystine-glutamate antiporter function in the nucleus accumbens promotes cocaine-induced drug seeking. Neuroscience. 2008;155(2):530-537.

62. Moran MM, McFarland K, Melendez RI, Kalivas PW, Seamans JK. Cystine/glutamate exchange regulates metabotropic glutamate receptor presynaptic inhibition of excitatory transmission and vulnerability to cocaine seeking. J Neurosci. 2005;25(27):6389-6393.

63. Danbolt NC. Glutamate uptake. Prog Neurobiol. 2001;65(1):1-105.

64. Pendyam S, Mohan A, Kalivas PW, Nair SS. Computational model of extracellular glutamate in the nucleus accumbens incorporates neuroadaptations by chronic cocaine. Neuroscience. 2009;158(4):1266-1276.

65. Lull ME, Freeman WM, Vrana KE, Mash DC. Correlating human and animal studies of cocaine abuse and gene expression. Ann N Y Acad Sci. 2008;1141:58-75.

66. Cunha-Oliveira T, Rego AC, Oliveira CR. Cellular and molecular mechanisms involved in the neurotoxicity of opioid and psychostimulant drugs. Brain Res Rev. 2008;58(1):192-208.

67. Alvaro-Bartolomé M, La Harpe R, Callado LF, Meana JJ, GarcíaSevilla JA. Molecular adaptations of apoptotic pathways and signaling partners in the cerebral cortex of human cocaine addicts and cocainetreated rats. Neuroscience. 2011;196:1-15.

68. Brown TE, Lee BR, Ryu V, Herzog T, Czaja K, Dong Y. Reducing hippocampal cell proliferation in the adult rat does not prevent the acquisition of cocaine-induced conditioned place preference. Neurosci Lett. 2010;481(1):41-46.

69. Toda S, Shen HW, Peters J, Cagle S, Kalivas PW. Cocaine increases actin cycling: effects in the reinstatement model of drug seeking. J Neurosci. 2006;26(5):1579-1587.

70. Kourrich S, Rothwell PE, Klug JR, Thomas MJ. Cocaine experience controls bidirectional synaptic plasticity in the nucleus accumbens. J Neurosci. 2007;27(30):7921-7928. 
71. Cingolani LA, Goda Y. Actin in action: the interplay between the actin cytoskeleton and synaptic efficacy. Nat Rev Neurosci. 2008;9(5): 344-356.

72. Ono S. Regulation of actin filament dynamics by actin depolymerizing factor/cofilin and actin-interacting protein 1: new blades for twisted filaments. Biochemistry. 2003;42(46):13363-13370.

73. Krause M, Dent EW, Bear JE, Loureiro JJ, Gertler FB. Ena/VASP proteins: regulators of the actin cytoskeleton and cell migration. Annu Rev Cell Dev Biol. 2003;19:541-564.

74. May RC. The Arp $2 / 3$ complex: a central regulator of the actin cytoskeleton. Cell Mol Life Sci. 2001;58(11):1607-1626.

75. Wolf ME. The Bermuda Triangle of cocaine-induced neuroadaptations. Trends Neurosci. 2010;33(9):391-398.

76. Ishikawa M, Mu P, Moyer JT, et al. Homeostatic synapse-driven membrane plasticity in nucleus accumbens neurons. J Neurosci. 2009; 29(18):5820-5831.

77. Mu P, Moyer JT, Ishikawa M, et al. Exposure to cocaine dynamically regulates the intrinsic membrane excitability of nucleus accumbens neurons. J Neurosci. 2010;30(10):3689-3699.

78. Kourrich S, Thomas MJ. Similar neurons, opposite adaptations: psychostimulant experience differentially alters firing properties in accumbens core versus shell. J Neurosci. 2009;29(39): 12275-12283.

79. Zhang XF, Hu XT, White FJ. Whole-cell plasticity in cocaine withdrawal: reduced sodium currents in nucleus accumbens neurons. J Neurosci. 1998;18(1):488-498.

80. Hu XT, Ford K, White FJ. Repeated cocaine administration decreases calcineurin (PP2B) but enhances DARPP-32 modulation of sodium currents in rat nucleus accumbens neurons. Neuropsychopharmacology 2005;30(5):916-926.

81. Hu XT. Cocaine withdrawal and neuro-adaptations in ion channel function. Mol Neurobiol. 2007;35(1):95-112.

82. Dong Y, Green T, Saal D, et al. CREB modulates excitability of nucleus accumbens neurons. Nat Neurosci. 2006;9(4):475-477.

83. Self DW, Nestler EJ. Relapse to drug-seeking: neural and molecular mechanisms. Drug Alcohol Depend. 1998;51(1-2):49-60.

84. Self DW, Genova LM, Hope BT, Barnhart WJ, Spencer JJ, Nestler EJ. Involvement of cAMP-dependent protein kinase in the nucleus accumbens in cocaine self-administration and relapse of cocaine-seeking behavior. J Neurosci. 1998;18(5):1848-1859.

85. Kalivas PW, Hu XT. Exciting inhibition in psychostimulant addiction. Trends Neurosci. 2006;29(11):610-616.

86. Karila L, Reynaud M, Aubin HJ, et al. Pharmacological treatments for cocaine dependence: is there something new? Curr Pharm Des 2011;17(14):1359-1368.

87. Nuijten M, Blanken P, van den Brink W, Hendriks V. Cocaine Addiction Treatments to improve Control and reduce Harm (CATCH): new pharmacological treatment options for crack-cocaine dependence in The Netherlands. BMC Psychiatry. 2011;11:135.

88. Amen SL, Piacentine LB, Ahmad ME, et al. Repeated N-acetyl cysteine reduces cocaine seeking in rodents and craving in cocaine-dependent humans. Neuropsychopharmacology. 2011;36(4):871-878.

89. Larowe SD, Kalivas PW, Nicholas JS, Randall PK, Mardikian PN, Malcolm RJ. A double-blind placebo-controlled trial of N-acetylcysteine in the treatment of cocaine dependence. Am J Addict. 2013;22(5): 443-452.

90. Schmaal L, Veltman DJ, Nederveen A, van den Brink W, Goudriaan AE. $\mathrm{N}$-acetylcysteine normalizes glutamate levels in cocaine-dependent patients: a randomized crossover magnetic resonance spectroscopy study. Neuropsychopharmacology. 2012;37(9):2143-2152.

91. Yang S, Salmeron BJ, Ross TJ, Xi ZX, Stein EA, Yang Y. Lower glutamate levels in rostral anterior cingulate of chronic cocaine users - A (1) H-MRS study using TE-averaged PRESS at $3 \mathrm{~T}$ with an optimized quantification strategy. Psychiatry Res. 2009;174(3):171-176.

92. Anderson AL, Reid MS, Li SH, et al. Modafinil for the treatment of cocaine dependence. Drug Alcohol Depend. 2009;104(1-2): 133-139.
93. Martinez-Raga J, Knecht C, Cepeda S. Modafinil: a useful medication for cocaine addiction? Review of the evidence from neuropharmacological, experimental and clinical studies. Curr Drug Abuse Rev. 2008;1(2): 213-221.

94. Dackis CA. Recent advances in the pharmacotherapy of cocaine dependence. Curr Psychiatry Rep. 2004;6(5):323-331.

95. Malcolm R, Swayngim K, Donovan JL, et al. Modafinil and cocaine interactions. Am J Drug Alcohol Abuse. 2006;32(4):577-587.

96. Hart CL, Haney M, Vosburg SK, Rubin E, Foltin RW. Smoked cocaine self-administration is decreased by modafinil. Neuropsychopharmacology. 2008;33(4):761-768.

97. Kampman KM. What's new in the treatment of cocaine addiction? Curr Psychiatry Rep. 2010;12(5):441-447.

98. Kampman KM, Pettinati H, Lynch KG, et al. A pilot trial of topiramate for the treatment of cocaine dependence. Drug Alcohol Depend. 2004;75(3):233-240.

99. Kampman KM, Dackis C, Pettinati HM, Lynch KG, Sparkman T, O'Brien CP. A double-blind, placebo-controlled pilot trial of acamprosate for the treatment of cocaine dependence. Addict Behav. 2011;36(3): 217-221.

100. Epstein DH, Preston KL, Stewart J, Shaham Y. Toward a model of drug relapse: an assessment of the validity of the reinstatement procedure. Psychopharmacology (Berl). 2006;189(1):1-16.

101. Tempesta E, Janiri L, Bignamini A, Chabac S, Potgieter A. Acamprosate and relapse prevention in the treatment of alcohol dependence: a placebo-controlled study. Alcohol Alcohol. 2000;35(2): 202-209.

102. Sass H, Soyka M, Mann K, Zieglgänsberger W. Relapse prevention by acamprosate. Results from a placebo-controlled study on alcohol dependence. Arch Gen Psychiatry. 1996;53(8):673-680.

103. Moghaddam B, Javitt D. From revolution to evolution: the glutamate hypothesis of schizophrenia and its implication for treatment. Neuropsychopharmacology. 2012;37(1):4-15.

104. Cohen-Solal JFG, Diamond B. Neuropsychiatric lupus and autoantibodies against ionotropic glutamate receptor (NMDAR). Rev Med Interne. 2011;32(2):130-132. French [with English abstract].

105. Contractor A, Mulle C, Swanson GT. Kainate receptors coming of age: milestones of two decades of research. Trends Neurosci. 2011;34(3):154-163.

106. Gross C, Berry-Kravis EM, Bassell GJ. Therapeutic strategies in fragile $\mathrm{X}$ syndrome: dysregulated mGluR signaling and beyond. Neuropsychopharmacology. 2012;37(1):178-195.

107. Jamain S, Betancur C, Quach H, et al; Paris Autism Research International Sibpair (PARIS) Study. Linkage and association of the glutamate receptor 6 gene with autism. Mol Psychiatry. 2002;7(3): 302-310.

108. Shuang M, Liu J, Jia MX, et al. Family-based association study between autism and glutamate receptor 6 gene in Chinese Han trios. Am J Med Genet B Neuropsychiatr Genet. 2004;131B(1):48-50.

109. Kim SA, Kim JH, Park M, Cho IH, Yoo HJ. Family-based association study between GRIK2 polymorphisms and autism spectrum disorders in the Korean trios. Neurosci Res. 2007;58(3):332-335.

110. Dutta S, Das S, Guhathakurta S, et al. Glutamate receptor 6 gene (GLuR6 or GRIK2) polymorphisms in the Indian population: a genetic association study on autism spectrum disorder. Cell Mol Neurobiol. 2007;27(8):1035-1047.

111. Sampaio AS, Fagerness J, Crane J, et al. Association between polymorphisms in GRIK2 gene and obsessive-compulsive disorder: a family-based study. CNS Neurosci Ther. 2011;17(3):141-147.

112. Delorme R, Krebs MO, Chabane N, et al. Frequency and transmission of glutamate receptors GRIK2 and GRIK3 polymorphisms in patients with obsessive compulsive disorder. Neuroreport. 2004;15(4): 699-702.

113. Schiffer HH, Heinemann SF. Association of the human kainate receptor GluR7 gene (GRIK3) with recurrent major depressive disorder. Am J Med Genet B Neuropsychiatr Genet. 2007;144B(1): 20-26. 
114. Mulle C, Sailer A, Pérez-Otaño I, et al. Altered synaptic physiology and reduced susceptibility to kainate-induced seizures in GluR6-deficient mice. Nature. 1998;392(6676):601-605.

115. Vissel B, Royle GA, Christie BR, et al. The role of RNA editing of kainate receptors in synaptic plasticity and seizures. Neuron. 2001;29(1):217-227.

116. Smolders I, Bortolotto ZA, Clarke VR, et al. Antagonists of GLU(K5)containing kainate receptors prevent pilocarpine-induced limbic seizures. Nat Neurosci. 2002;5(8):796-804.

117. Pickard BS, Malloy MP, Christoforou A, et al. Cytogenetic and genetic evidence supports a role for the kainate-type glutamate receptor gene, GRIK4, in schizophrenia and bipolar disorder. Mol Psychiatry. 2006;11(9):847-857.

118. Moghaddam B, Jackson ME. Glutamatergic animal models of schizophrenia. Ann NY Acad Sci. 2003;1003:131-137.

119. Goff DC, Coyle JT. The emerging role of glutamate in the pathophysiology and treatment of schizophrenia. Am J Psychiatry. 2001;158(9): 1367-1377.

120. Mohn AR, Gainetdinov RR, Caron MG, Koller BH. Mice with reduced NMDA receptor expression display behaviors related to schizophrenia. Cell. 1999;98(4):427-436
121. Ballard TM, Pauly-Evers M, Higgins GA, et al. Severe impairment of NMDA receptor function in mice carrying targeted point mutations in the glycine binding site results in drug-resistant nonhabituating hyperactivity. J Neurosci. 2002;22(15):6713-6723.

122. Pellegrino D, Cicchetti F, Wang X, et al. Modulation of dopaminergic and glutamatergic brain function: PET studies on parkinsonian rats. J Nucl Med. 2007;48(7):1147-1153.

123. Phillips JM, Lam HA, Ackerson LC, Maidment NT. Blockade of mGluR glutamate receptors in the subthalamic nucleus ameliorates motor asymmetry in an animal model of Parkinson's disease. Eur J Neurosci. 2006;23(1):151-160.

124. Ambrosi G, Armentero MT, Levandis G, Bramanti P, Nappi G, Blandini F. Effects of early and delayed treatment with an mGluR5 antagonist on motor impairment, nigrostriatal damage and neuroinflammation in a rodent model of Parkinson's disease. Brain Res Bull. 2010;82(1-2):29-38.

125. Black YD, Xiao D, Pellegrino D, Kachroo A, Brownell AL, Schwarzschild MA. Protective effect of metabotropic glutamate mGluR5 receptor elimination in a 6-hydroxydopamine model of Parkinson's disease. Neurosci Lett. 2010;486(3):161-165.
Neuropsychiatric Disease and Treatment

\section{Publish your work in this journal}

Neuropsychiatric Disease and Treatment is an international, peerreviewed journal of clinical therapeutics and pharmacology focusing on concise rapid reporting of clinical or pre-clinical studies on a range of neuropsychiatric and neurological disorders. This journal is indexed on PubMed Central, the 'PsycINFO' database and CAS.

\section{Dovepress}

The manuscript management system is completely online and includes a very quick and fair peer-review system, which is all easy to use. Visit $\mathrm{http}: / / \mathrm{www}$.dovepress.com/testimonials.php to read real quotes from published authors. 